\title{
Study on Easing Public Transport Congestion in Beijing Based on Management Model in Australia
}

\author{
Hongchang An \\ Department of Safety Engineering, China Institute of Industrial Relations, Beijing, China
}

Email address:

anhongchang@126.com

To cite this article:

Hongchang An. Study on Easing Public Transport Congestion in Beijing Based on Management Model in Australia. Social Sciences. Vol. 5, No. 4, 2016, pp. 54-57. doi: 10.11648/j.ss.20160504.11

Received: July 17, 2016; Accepted: July 28, 2016; Published: August 10, 2016

\begin{abstract}
Traffic congestion in Beijing is obvious to all. Especially, it is daunting during the peak hours. The harms it causes are well known. Relevant governmental departments have taken some measures, but the effect is not obvious. Successful foreign experience shows that the first priority of solving the traffic congestion is to solve the problem of public transport congestion. Public transport congestion in Beijing is very serious for everyone. Australia is one of the countries in the world that is recognized public traffic management well. Therefore, by combing the Australian public traffic management measures and referring to public traffic management in Beijing according to subway and bus as main public transports in Beijing, public transport congestion in Beijing will be improved, and the traffic congestion in Beijing will be improved, and Beijing will be more beautiful, and better life in Beijing will be made.
\end{abstract}

Keywords: Public Transport, Congestion, Beijing, Australia, Punctual Arrival, Bus First

\section{Introduction}

Traffic congestion in Beijing is obvious to all. Especially, it is daunting during the peak hours. The harms that it causes are well known. Relevant governmental departments have taken some measures, but the effect is not obvious. Successful foreign experience shows that the first priority of solving the traffic congestion is to solve the problem of public transport congestion. Public transport congestion in Beijing is very serious for everyone such as overcrowded on the subway during the peak hours, crowded on the bus and a serious blockage during the rush hours. Solving the traffic congestion in Beijing should also begin from the solution to public transport congestion in Beijing. To solve public transport congestion in Beijing is not only part of solution to the traffic congestion in Beijing, is to solve the congestion problem in itself, also can attract non public transport to reduce travel and in turn help solve the public transport congestion in Beijing, and this will form a virtuous circle. On the contrary, if the governments do not solve the public transport congestion in Beijing, traffic congestion in Beijing and the congestion problem in itself will not be solved, this will not be able to attract non public transport to travel less, or even to encourage non public transport to travel more so as to increase the public transport congestion in Beijing, and this will form a vicious circle. If public transport congestion in Beijing cannot be solved fundamentally, even if all non public vehicles are stopped, public transport congestion in Beijing still exists and traffic congestion in Beijing will also exist. Some people can say that when all non public vehicles stop, solving public transport congestion in Beijing will be getting easy. In fact, this is impossible; difficulty of both conditions is same and that non public vehicles are supplementary to public transport is irrefragable. Public transport congestion in Beijing has come to the urgent situation, since 2016 Beijing's governmental projects involving a number of related issues can be seen. The 2022 Winter Olympics will come to Beijing, it is now necessary to issue a warning: if the governments do not ease public transport congestion in Beijing as soon as possible, traffic and public transport in Beijing after the 2022 Winter Olympics is as bad as, or even worse than one after 2008 Olympic Games. If the governments want to take this as an opportunity to improve the traffic in Beijing, to improve the public transport in Beijing, they must find a series of measures of easing public transport congestion in Beijing as soon as possible, and cannot fear and wait for anything.

Traffic congestion in some cities in Australia is also very serious, but their public transport has been recognized as 
relatively good in the world. The author has lived in Sydney, Australia for one year, and has a deep understanding of it. Learning from the Australian public transport management model for Beijing to solve public transport congestion, and then solving a certain degree of traffic congestion in Beijing has a great value.

\section{Related Works}

Main roads are two-way and parking is permitted on their both side; secondary roads are one-way for cars and two-way for buses; other roads are one-way and parking is permitted on its half; active toll stations are used to reduce the congestion during charging; there are clear traffic signs for slow speed and stop to give way; there are portal display and monitoring system every two kilometers; scoring offense requires more stringent penalties; parking fees are charged with the coin collecting; accident claims handling is easy [1].

Bus riding is free before 7:00 AM in Melbourne; all buses will arrive at the corresponding stop according to a rough schedule [2].

Speeding will attract heavy penalties and even cause the immediate revocation of the driving license in Sydney; vehicles run on its roads, there is little condition for doubling and overtaking; highways in Sydney are freeway; buses are of good quality, safe and reliable; buses arrive at the stop on time, otherwise passengers can apply for compensation through complaints [3].

Some of the city's roads and bridges in Australia realize the traffic in real-time control and guide, make good use of road resources in a certain degree, optimize order way, avoid the traffic congestion by setting signal light to change the direction of road traffic; special lanes are for the cars with more than two persons; the versatility and flexibility of parking on the roadside are done; vehicles have speed limit in themselves [4].

Traffic lights make humanized design; pedestrians, buses, or private cars, whether it is in left turn, right turn, or straight going, will in turn release; traffic safety publicity grabs from baby; strict penalties is for traffic violations, the installation and the usage of "black box" is done; special sections of the lane have adjustment system, 4-minute comprehensive emergency rescue exists in the city of Sydney [5].

Sidewalks have walking signs; it is very strict for a driver to obtain and use driving license; wine driving testers are equipped with some cars; police does explicit and implicit patrol [6].

Traffic signs are full; civilized traffic begins from education [7].

Planning and management must cooperate with each other; car and bus are in control; bus guides urban development first [8].

Electronic surveillance system constantly monitors all kinds of vehicles, accurately issue information to the center control room when the roads are in violation of regulations or congestion occurs; traffic police may take drunk driver home [9].

The vehicle horn is banned to use on the road in the city; to take over the overtaking lane for a long time is banned; automatic parking fee system is used [10].

VTS center establishes bus priority mechanism in collaboration with Department of Transportation of the State, the priority mechanism includes delimiting the bus lanes, increasing bus stops harbors, and recently putting public transportation information system into use. The system will integrate bus schedule and signal lights control system for bus priority and longer time to provide priority bus [11].

There exist the main characteristics of humanization and heavy penalties in new road traffic regulations [12].

Traffic participants abide by the traffic law [13].

Pre-sale ticket lines, free link buses, tour buses with 24-hour ticket are used [14].

\section{Valuable Australian Measures for Beijing to Ease Public Transport Congestion}

\subsection{Rail Transit-Taking Sydney as an Example}

For rail transit in Sydney, there are features below:

(1) Arrival on time

The train can arrive at exactly the right time. This is one of the strengths of rail transit, but the precondition is good guarantee.

(2) Variety of ways to run

The trains with the same line can be divided into all-stop trains and interval-stop trains. There exists the different frequency in different periods of time.

(3) Variety of tickets

Tickets with different fares, such as one-way tickets, return tickets, day tickets, weekly tickets, monthly tickets, family tickets are adopted. Especially, there are different fares in different time.

(4) Transfer under special conditions

In line maintenance and other special circumstances, very good transfer buses are arranged. Transfer between train and bus is convenient.

(5) Many free parking spaces near the stations outside the city

The stations outside the city have many free parking spaces, but the standard parking is required, otherwise it will be fined. Crowded places such as shopping centers, supermarkets provide two-hour or three-hour free parking spaces.

(6) Large volume of the carriage

The carriages of the train are many and have two layers. The seats in the carriage are turnover.

(7) Operational security

Timely warranty of vehicles and tracks and related facilities are planned.

\subsection{Bus-Take Sydney as an Example}

For bus in Sydney, there are features below:

(1) Arrival on time

Not only Sydney's rail transit arrives on time, the bus traffic in Sydney is also very punctual arrival. Buses arrive at the 
same stop at the order of time, there are not two or more buses arriving at the same stop at the same time, the hub station can be docked more than a bus to be transported. In order to ensure buses arriving at the stop on time, buses run first by private drivers' being conscious to give way, being reminded to give way and being forced to give way, buses are in good condition, bus drivers obey civilized rules.

(2) Full coverage

Buses can not only reach wherever the rail transit reaches, but also can reach wherever the rail transit cannot reach. People almost can easily find the bus stop nearby.

(3) Bus modernization

Buses are of high quality, equipped with a complete range of related facilities. Bus modernization is not only the guarantee of the arrival time, while riding is comfortable.

(4) Variety of tickets

There are different tickets. People can buy tickets in the convenience store and other places in advance, but also buy them on the bus. Tickets are divided into one-section, two-section and three-section tickets, also into one-way and return tickets.

(5) Civilized riding

Queue up in order to get on the bus, pay attention to health, and keep the number of restrictions, the driver competent and illegal punishment.

(6) Road management

Road keeps specifications, clear signs. Different roads adopt different management modes. Urban roads are planned and managed intelligently and in detail.

\section{The Idea of Easing Public Transport Congestion in Beijing According to Australian Measures}

\subsection{Subway}

Compared with Sydney, the current subway in Beijing has been developed. But the diversity and flexibility of management is of a big difference.

Below are the measures for easing subway congestion in Beijing:

(1) Arrival on time

This has been done, but the occasional failure should try to be avoided.

(2) Variety of ways to run

This is the most worthy concern of subway in Beijing, for the dispersion of people and the protection of subway are very important and safe. The frequency in different period and stopping mode in different stations should be adjusted and planned to disperse people and protect subway.

(3) Variety of tickets

This is also worthy of reference, in particular, different period fare program to ease congestion is significant, and is also successful international experience.

(4) Transfer under special conditions

This reference is not too great, but to solve the problem of public transport with the bus cooperate is worth trying. Shortening the distances between the station and the bus stop is welcome and necessary.

(5) Many free parking spaces near the stations outside the center of the city

This is also very worthy of reference. More free parking spaces nearby the stations should be provided by self-building, renting, collecting, imposing parking places nearby the stations.

(6) Operational security

This can be done, but still should be strengthened. The rational use of the advantages of China feature system should be made completely, but people cannot let down to make careless blunder.

\subsection{Bus}

Below are the measures for easing bus congestion in Beijing:

(1) Arrival on time

This is the biggest problem in Beijing, is one of important reasons to give up the bus and drive car and ride subway. The first step of improving the bus congestion is to arrive at the stop on time according to bus first. For bus first, the implementation of private drivers' being conscious to give way, being reminded to give gay, being forced to give way is required; this still needs to guarantee the buses, buy and use high quality buses and related complete facilities and equipment, high quality drivers and driving civilization are required, and there are restrictions on the number of passengers.

(2) Full coverage

The government must adjust the layout of the bus lines, reduce the lines in the subway coverage area, and cover the area subway cannot cover. This is a very challenging task, but it is imperative. Especially, bus lines are adjusted according to Australian model to keep only a bus at one stop. In other words, the bus arrival time at every bus stop is arranged at the order of time and requires that there are not two or more buses arriving at the same stop at the same time.

(3) Bus modernization

This is also very worthy of reference, the current buses in Beijing are really too bad. The government should strengthen bus management to provide high quality and convenience. That buses are often in fault or in accidents in the roads is one of the reasons to cause public transport congestion and traffic congestion in Beijing.

(4) Variety of tickets

This can be used for reference, such as free or half price before 7 o'clock AM. Ticket pricing mechanism is the important measure to ease public transport congestion in Beijing. Rational ticket price should be scientifically made to ease bus congestion in Beijing.

(5) Civilized riding

Make more strict rules of the bus riding and strengthen the law enforcement. Especially, unscientific arrangements such as irrational ticket payer setting, the middle gate for getting on should be cancelled. This aspect needs more improvements in 
Beijing. Every person is both victim and beneficial owner of public transport congestion and traffic congestion in Beijing.

(6) Road management

To strengthen the management of the road, the effective use of road resources, more use of a single line, road specifications and clear signs is needed. Roads should be divided into main roads, secondary roads, and others and should be managed with two-way or one-way. Vehicles should have access priority according to bus, special vehicle, taxi, more persons' vehicle, and so on. Vehicles in an accident and in fault to cause traffic congestion and public transport congestion should be highly punished.

\section{Conclusion}

Public transport in Beijing has obvious problems, and there are many factors to influence the public transport congestion in Beijing. But Australian public transport policies and measures are worth reference in Beijing. On the basis of adopting some of the above mentioned important and practical measures in priority, and constantly improving the condition of the roads, guiding private vehicles to run in rules, strengthening all kinds of traffic participants' civilization traffic training, and limiting the number of nonlocal vehicles according to subway and bus as main public transports in Beijing will gradually ease the public transport congestion in Beijing, let public transport in Beijing be like that in Sydney as well, let Beijing have better traffic, be with better traffic and other environment, create Beijing for the good, and create a better life.

\section{Acknowledgement}

This paper is supported by General Research Project (14YY001) from China Institute of Industrial Relations.

\section{References}

[1] Liming Wei. Feeling Traffic in Australia. Road Traffic Management. No. 5, 2015, pp. 80-81.
[2] Xiaozhou He, Ying Dong. Persistent Stick and Historical Heritage-Investigation Report for Public Transport in Melbourne, Australia. Jiangsu Urban Planning. No. 3, 2014, pp. $39-42$.

[3] Bo Tang. A Glance at Transportation and Logistic Service of Australia. Commercial Vehicle. No. 5, 2013, pp. 88-91.

[4] Wenxiang Ling. Transport Management in Australia. Safety and Health. No. 20, 2012, pp. 26.

[5] Baocun Hu, Shisheng Wu. Feeling Transport in Australia. Road Machinery \& Construction Mechanization, No. 5, 2012, pp. 7-10.

[6] Feihua Chen. Civilized Traffic in Australia. Old Friend. No. 6, 2011, pp. 49.

[7] Lubiao Xi, Yan Liu, Wei Chen. Experience of Safety and Smooth Flow at the Times of Car-Investigation of Road Traffic Management in Australia and New Zealand. Road Traffic Management. No. 1, 2011, pp. 54-58.

[8] Jing Li, Aggie, Gary Hynson. Australia Seeks to Actively Participate in the Construction of Traffic-Smooth Chongqing-Interview with Richard Filewood, the Regional Manager Asia of Australia MRC Company. The World and Chongqing. No. 12, 2010, pp. 50-55.

[9] Yanwen Xu. A Glance at Traffic in Australia. Traffic and Transportation. No. 5, 2010, pp. 65.

[10] Qishu Chen. Impression of the Australian Road Transport. Safety and Health. No. 6, 2010, pp. 22.

[11] Haiying Ning. Investigation of Road Traffic Management at the Center of New South Wales, Australia. Road Traffic and Safety. Vol. 8, No. 3, 2008, pp. 61-64.

[12] Ying Jiang. New Changes of the Road Traffic Regulations in New South Wales, Australia. Road Traffic and Safety. Vol. 8, No. 4, 2008, pp. 54-57.

[13] Chunhua Wang. Transport in Australia. Traffic and Transportation. No. 2, 2006, PP. 25.

[14] Zhiyue Yu. Feeling Transport in Sydney. Traffic and Transportation. No. 2, 2014, pp. 59-61. 